\title{
Problems of Application Analysis in Knowledge Management and Science-Mathematics-Education
}

\author{
Alex Maritz ${ }^{1 *}$, Tung-Ju Wu ${ }^{2}$, Wan-Yu Chang ${ }^{3}$ \\ ${ }^{1}$ La Trobe Business School, La Trobe University, AUSTRALIA \\ ${ }^{2}$ College of Business Administration, Huaqiao University, Quanzhou, CHINA \\ ${ }^{3}$ Department of Tourism and MICE, Chung Hua University, Hsinchu, TAIWAN
}

Received 5 November 2017 - Revised 6 November 2017 • Accepted 7 November 2017

In the knowledge-based economic era, organizations have gradually realized that "people" are the key assets in an organization. The quality of internal human resources of an organization would be the key success factor in the fiercely competitive market nowadays. Accordingly, it becomes extremely important to educate and enhance the quality of internal human resources in an organization by promoting science and mathematics education. Knowledge is the core of civilization as well as the basis of humans thinking, relying, and questioning the essence of civilization. The progress of knowledge has technology emerge and change the world. Although knowledge has been an academic subject for long, Knowledge Management (KM) is considered as an emerging subject. The appearance of large amount of available information in modern societies has science and mathematics education present the importance.

In addition to the professional development of employees, organizational culture, technology equipment, and science and mathematics education are the key elements in the promotion of KM. Introducing the philosophy of $\mathrm{KM}$ into organizations aims to enhance the professional development of employees in order to cope with the changeable and unpredictable industrial environment. Under the influence of knowledge-based economy, the organization restructuring, organizational renewal, manufacturing production innovation, and employee team learning are the new development trends of an enterprise. Following the progress of information technology and the emergence of $\mathrm{KM}$, the competitive advantage of tangible assets is gradually replaced by intangible intellectual capital. Science and mathematics education is an effective route for experience inheritance, culture development, and knowledge creation. It therefore becomes a major challenge for education and the key success factor in enterprise assisting the employees in sharing and exchanging knowledge with others and sustainably developing the knowledge through science and mathematics education in the knowledge-based economic era.

KM promoted by an enterprise mostly aims at the accumulated knowledge and the collected, analyzed, and reutilized existing knowledge. A lot of enterprise owners even consider that "KM" could be achieved by document management and information management. However, such knowledge can merely preserve and use explicit knowledge, but could not have the value of knowledge be really effectively flipped and even create larger benefits for the enterprise. The KM process lies in "knowledge acquisition", "knowledge transfer", "knowledge sharing", and "knowledge innovation" through data mining for the transformation from information to knowledge and to realize with science and mathematics education. Knowledge discovery and learning are the intellectualized embodiment. Knowledge discovery is not simply completed in the knowledge base, but would exchange in various application systems and the procedures of knowledge processing. The embodiment of value of the entire KM system is based on knowledge discovery and knowledge learning as well as the application of information and knowledge, through data mining, to the decision-making of an enterprise to formulate new marketing plans, provide more new products for target users, and put such plans into practice.

Big data, a popular topic in past years, refers to a basket of skills and relevant knowledge to analyze and organize large data sets and to find out regularity and make predictions. Since there is precious information in big data, such as correlations, invisible models, and market trends, unprecedented knowledge and application might be there for being discovered. For this reason, applying efficient science and mathematics education to make works be more efficient and effective and to enhance and reinforce the value of knowledge becomes significant and meaningful. In other words, being able to dealing with and understand big data is an essential skill in various domains. Nevertheless, science and mathematics education is critical to match with the requirement of the information world. Science and mathematics education could cultivate information literacy and problem-solving capability, enhance the information acquired from data mining in the KM, and promote the analysis and application of data in KM. 
KM stresses on the promotion of internal information technology of an organizations being able to drive knowledge delivery and sharing. It is considered that good knowledge flow and innovation in an organization could largely enhance the employees' effectiveness. In regard to personnel management, the observation learning among members, in addition to the collection and analysis of information, is emphasized to promote organizational effectiveness to further promote organizational competitiveness. Apparently, KM is the process of people externalizing tacit knowledge to have the organization effectively apply knowledge. Moreover, KM is the process to link the entire knowledge chain, including the skills required for knowledge awareness and confirmation, the development of new skills, the communications of new skills, the application of new skills, and the elimination of old skills. Regarding the application and discussion of KM, managing knowledge in individuals, departments, and units in an enterprise with science and mathematics education is to systematically collect and organize experiences, technologies, and intelligence in the enterprise for the acquisition or application of personnel in the organization. The practice of science and mathematics education to organizational members could enhance the organizational effectiveness.

The special issues of Problems of Application Analysis in KM and Science-Mathematics-Education, involve mathematical education used in science, engineering, economics and industry. Therefore, the application of mathematics is the combination of Science-Mathematics-Education. The term" Problems of Application Analysis in KM and Science-Mathematics-Education" also describes the professionalism of mathematicians through the development and research of mathematical education to deal with practical problems. In the past, the practical application has stimulated the development of mathematical theory, and then become a purely mathematical research topic, in order to learn abstract concepts. Therefore, the mathematical activities and the application of pure mathematics research is closely related.

The purpose of this special issue is to provide a forum for introducing current research and discussing future research directions in the "Problems of Application Analysis in KM and Science-Mathematics-Education" to develop academic challenges. On this special issue, we received a total of 152 papers and accepted 45 papers. The decisions we chose the papers are based on the originality, Science-Mathematics-Education, practical contribution and relevance. In addition to the guest editor, at least 2 or 3 referees are assigned in each submission.

The guest editors wishes the papers published in this issue will be valuable for academic research and practical value, and will provide clearer guidance for future researchers and encourage researchers to explore more creative contributions. The guest editors would like to thanks to the staffs of the journal office of EURASIA Journal of Mathematics, Science and Technology Education.

\section{http://www.ejmste.com}

